\title{
FORMAÇÃO DA IDENTIDADE EM ÂMBITO HIPERCULTURAL: CORPOREIDADE E FILOSOFIA
}

\author{
LEONARDO DIAS AVANÇO \\ ORCID: https://orcid.org/0000-0002-3468-3888 \\ JOSÉ MILTON DE LIMA ${ }^{2}$ \\ ORCID: https://orcid.org/0000-0001-5519-2618 \\ MARCOS GARCIA NEIRA ${ }^{3}$ \\ ORCID: https://orcid.org/0000-0003-1054-8224
}

\begin{abstract}
RESUMO: Neste artigo, reconstitui-se um repertório filosófico com o objetivo de enfrentar problemas relativos a importantes transformações atuais no âmbito da cultura e da educação, enfocando-se mais propriamente a questão da formação de identidades no âmbito da hipercultura em sua relação com a dimensão da corporeidade. Do ponto de vista do caminho metodológico, em primeiro lugar, são delineadas as noções de e as relações entre globalização, ciberespaço e hipercultura; em uma segunda etapa, passa-se a fundamentar filosoficamente uma nova noção de identidade vinculada a mudança de paradigma e a uma contribuição com os estudos da corporeidade. A título de conclusão, expõe-se uma síntese e uma orientação filosófica relacionada à formação humana em tempos de expansão hipercultural, de modo que são aludidas possibilidades educativas de formação da identidade em consonância com um novo paradigma de compreensão da realidade e da corpoereidade humana em sua integralidade e conexão, o qual emerge, em parte, de resultados da ciência física moderna, mas que, de outro lado, não deixa de reencontrar raízes em formas milenares de sabedoria.
\end{abstract}

Palavras-chave: Hipercultura, Educação, Ciberespaço.

\section{FORMATION OF IDENTITY IN THE HYPERCULTURAL SCENARIO: CORPOREITY AND PHILOSOPHY}

ABSTRACT: In this article, a philosophical repertoire is reconstructed in order to face problems related to important current transformations in the scope of culture and education, focusing more specifically on the issue of the formation of identities within the scope of hyperculture in its relation to the dimension of corporeity. From the point of view of the methodological path, in the first place, the notions of and the relations between globalization, cyberspace and hyperculture are outlined; in a second step, a new notion of identity linked to the change of paradigms and a contribution to the studies of corporeality is philosophically grounded. As a conclusion, a synthesis and a philosophical orientation related to human formation in times of hypercultural expansion are exposed, while educational possibilities for the formation of identity are alluded in line with a new paradigm of understanding reality and human body

\footnotetext{
${ }^{1}$ Universidade Estadual Paulista (UNESP). São José do Rio Preto, SP, Brasil. <ldavanco87@gmail.com>

${ }^{2}$ Universidade Estadual Paulista (UNESP). Presidente Prudente, SP, Brasil. <milton.lima@unesp.br>

${ }^{3}$ Universidade de São Paulo (FEUSP). São Paulo, SP, Brasil. <mgneira@usp.br>
} 
in its wholeness and connection, which emerges, in part, from the results of modern physical science, but which, on the other hand, does not fail to find roots in ancient forms of wisdom.

Keywords: Hyperculture, Education, Cyberspace.

\section{FORMACIÓN DE IDENTIDAD EN UN CONTEXTO HIPERCULTURAL: CORPOREIDAD Y FILOSOFÍA}

RESÚMEN: En este artículo se reconstruye un repertorio filosófico para enfrentar problemas relacionados con importantes transformaciones actuales en el ámbito de la cultura y la educación, centrándose más específicamente en el tema de la formación de identidades en el ámbito de la hipercultura en su relación con la dimensión de corporeidad. Desde el punto de vista del camino metodológico, en primer lugar se esbozan las nociones y las relaciones entre globalización, ciberespacio e hipercultura; en una segunda etapa, se fundamenta filosóficamente una nueva noción de identidad ligada a un cambio de paradigma y una contribución a los estudios de la corporeidad. Como conclusión, se expone una síntesis y una orientación filosófica relacionada con la formación humana en tiempos de expansión hipercultural, de manera que las posibilidades educativas para la formación de la identidad se aludem en línea con un nuevo paradigma de comprensión de la realidad y el cuerpo humano en su integridad y conexión, que surge, en parte, de los resultados de la ciencia física moderna, pero que, por otro lado, no deja de encontrar raíces en formas antiguas de sabiduría.

Palabras clave: Hipercultura, Educación, Ciberespacio. 


\section{PRELÚDIO}

O questionamento acerca de nossa natureza, visando-se com isso a um melhor conhecimento de si, consiste em uma atividade que, em certas condições, pode ser experimentada por qualquer ser humano, independentemente de sua relação com esta ou aquela tradição cultural ou filosófica. Tal indagação pode ser realizada de diferentes formas, em variados contextos, a partir do uso de diversas linguagens, ao passo que os processos que ela ensaia podem seguir por distintos caminhos, encontrar respostas contrastantes entre si e atingir graus vários de complexidade, profundidade e amplitude. Heráclito de Éfeso - aquele que, após muito meditar, haveria dito: "eu me procurei a mim mesmo" (frag. 101) - já havia expressado essa dificuldade nos seguintes termos: "mesmo percorrendo todos os caminhos, jamais encontrarás os limites da alma, tão profundo é o seu Logos" (frg. 45) (HERÁCLITO, 1998, p. 36-46). Não obstante o seu caráter ilimitado e as possibilidades que enseja, a busca pelo conhecimento de si, daquilo que somos, em suma, de nossa identidade, é parte da condição humana, ao passo que, devido à dimensão de movimento e de transformação que é própria da realidade da qual somos parte, tal atividade, sob determinadas condições, pode emergir em diversos contextos de nossas vidas.

O ser humano interroga-se acerca de sua identidade de maneiras mais agudas desde o momento em que, supridas as suas necessidades básicas e imediatas, direciona a sua energia para uma observação desinteressada sobre a grandeza do mundo e sobre si mesmo. Os graus de intensidade, abrangência e profundidade de suas reflexões e práticas de conhecimento de si aumentaram à medida que foram estabelecidas condições para o desenvolvimento de atividades em contexto de ócio, isto é, ações cuja destinação energética não se vinculava a - ou, pelo menos, distanciavam-se decisivamente de finalidades imediatamente pragmáticas ou utilitárias. Como é sabido, o amor pela sabedoria e pelo conhecimento do mundo e de si - a philosophía -, no âmbito de povos diversos, implica uma variedade de ações que - ainda que valorizem em graus distintos a utilidade e uma orientação para a prática - são de certo modo protegidas do reino da necessitação, pois, assim como as atividades de desenvolvimento das ciências, possuem maiores afinidades com a liberdade e o jogo. Ainda que mais recentemente tenham sido assimiladas ao universo laboral (aumentando o potencial da indústria, dos transportes, da comunicação etc. no caso da ciência; e investindo a vida política de distinta reflexividade, no caso da filosofia), atividades de natureza científica e filosófica não perdem seu vínculo essencial com a dimensão propriamente lúdica da condição e da experiência humanas, cujo campo total não é captado por representações corriqueiramente limitantes e dominantes investidas em palavras associadas à ludicidade, tal como jogo, brincadeira etc.

De qualquer modo, correntes dominantes da história da filosofia euro-ocidental, ao situar determinadas formas de interpretar o helenismo como um marco de origem, privilegiaram a alma em detrimento do corpo, destacando-se de maneira particular uma concepção dual-conflituosa de ser humano no âmbito das reflexões sobre a sua identidade. Comprova-o o influxo de diversas espécies de platonismos na constituição de lugares-comuns sobre as questões relacionadas à alma e ao corpo. No período da Idade Média europeia, além da condição de subalterno e de empecilho para o desenvolvimento do espírito, o corpo foi também vilipendiado por determinadas vertentes da Igreja Católica. Com o advento da chamada Idade Moderna, o cartesianismo acirrou ainda mais o conflito entre alma e corpo, contribuindo decisivamente com a construção de uma concepção segundo a qual o corpo, em oposição à alma, não passaria de um sistema maquínico-mecânico a ser explicado primordialmente em seu aspecto anatômico-fisiológico. Atualmente, porém, compreendida enquanto importante área do saber e dimensão da experiência humana, a corporeidade passa a propiciar-nos um importante e complementar entendimento do "ser humano em sua condição existencial" (MOREIRA; SIMÕES, 2016, p. 137).

Ora, de acordo com Estermann (2006), enquanto a noção de substância constitui um dos principais mitos fundacionais do Ocidente, o senso de relacionalidade constitui parte central do mito fundacional da cosmovisão andina: "o que a ontologia ocidental chama 'ente' ('substância' em sentido aristotélico), para a racionalidade andina é um 'nó' de relações, um ponto de transição, uma concentração relacional". Essas distintas cosmovisões têm repercussões antropológicas significativas. Ainda que, considerando o desenvolvimento histórico europeu, os antigos e os medievais se sentissem inseridos "em um cosmos ordenado [...], começa paulatinamente uma desnaturalização do ser humano e uma desumanização da natureza, que chegam a seu ponto culminante com o dualismo cartesiano". Nesse 
sentido, particulares noções de individualidade e autonomia ganharam força cada vez maior na formação da identidade moderna, ao passo que, do ponto de vista andino, a desconexão com os vínculos naturais e cósmicos significaria firmar a própria "sentença de morte" (ESTERMANN, 2006, p. 107-110 tradução nossa). Mais adiante, veremos como essa concepção presente no repertório de saberes de povos ameríndios se aproxima de noções que subjazem parte considerável do pensamento cultivado no Extremo Oriente.

Considerando determinadas particularidades dos processos de globalização, este artigo estabelece o seguinte objetivo: a partir de uma renovação do repertório filosófico para o enfrentamento de problemas relativos às transformações atuais no âmbito da cultura e da educação, visa-se a contribuir com a compreensão de determinados aspectos cruciais do processo de formação da identidade em sua relação com a dimensão da corporeidade. Para tanto, em um primeiro momento, delineamos em perspectiva geral determinados aspectos de fenômenos culturais contemporâneos, articulando as noções de globalização, ciberespaço e hipercultura; em uma segunda parte, com base nos conceitos hauridos na primeira etapa, passamos a fundamentar filosoficamente uma outra noção de identidade, a partir da consideração da emergência de um novo paradigma de compreensão do mundo e do ser humano, vinculando-a a uma proposta que visa a contribuir com os estudos da corporeidade. Por fim, em tópico último, tecemos nossas considerações finais.

\section{GLOBALIZAÇÃO, CIBERESPAÇO E HIPERCULTURA}

Com o encerramento da Guerra Fria, por intermédio da concretização de potenciais tecnocientíficos e de estratégias mercadológicas de caráter transnacional, a última década do milênio passado testemunhou a "origem" de um processo singular de "integração" de povos. A integração de que se fala aqui é marcada por uma "proximidade" engendrada pelo uso de engenhos telecomunicacionais. Esse processo - que se configura como um dos traços fundamentais daquilo que se denomina globalização deu-se progressivamente, sobretudo, graças à expansão mundial da Internet, a qual acelerou como nunca a comunicação humana, a troca e o armazenamento de informações em um "oceano" virtual exponencialmente transbordante. É nesse contexto que emerge um fenômeno que tem transformado radicalmente a experiência existencial de grupos crescentes de seres humanos: o ciberespaço. De acordo com Lévy (2018, p.17), “o ciberespaço (que também chamarei de 'rede') é o novo meio de comunicação que surge da interconexão mundial dos computadores". O termo indica também especificamente "não apenas a infraestrutura material da comunicação digital, mas também o universo oceânico de informações que ele abriga, assim como os seres humanos que navegam e alimentam esse universo". Da delimitação desse fenômeno, deriva a noção de cibercultura, que "especifica aqui o conjunto de técnicas (materiais e simbólicas), de práticas, de atitudes, de modos de pensamento e de valores que se desenvolvem juntamente com o crescimento do ciberespaço" (LÉVY, 2018, p. 17).

De certa maneira, mesmo antes da queda do Muro de Berlim, já havia evidências de que mudanças substanciais estavam por vir. De Masi (2000) recorda que, já no fim da década de 1960, "princípios axiais" que confirmam a tendência de transição de uma sociedade industrial para uma sociedade pós-industrial já haviam sido identificados e teorizados. Considerando em síntese proposições de Daniel Bell, foram apontados cinco os "princípios axiais": [1] "a passagem da produção de bens à produção de serviços"; [2] "a crescente importância da classe de profissionais liberais e técnicos em relação à classe operária"; [3] "o papel central do saber teórico ou, como dirá Dahremdorf mais tarde, o primado das ideias"; [4] "o problema relativo à gestão do desenvolvimento técnico: a tecnologia tornouse tão poderosa e importante, que não pode mais ser administrada por indivíduos isolados e, em alguns casos-limite, nem mesmo por um só Estado"; [5] "a criação de uma nova tecnologia intelectual, ou seja, o advento de máquinas inteligentes, que são capazes de substituir o homem não só nas funções que requerem esforço físico, mas também nas que exigem esforço intelectual” (DE MASI, 2000, p. 111). Por outro lado, antes do advento da Internet, os computadores já haviam feito a sua aparição e foram aos poucos demonstrando um potencial de desenvolvimento que suplantaria em boa medida tanto o rádio como a televisão. Conforme aponta Lévy (2018, p. 45), o computador define-se como "uma montagem particular de unidades de processamento, de transmissão, de memória e de interfaces para entrada e saída de informações". À medida que, porém, conecta-se, via Internet, ao ciberespaço, essa máquina passa a 
"recorrer às capacidades de memória e de cálculo de outros computadores da rede (que, por sua vez, fazem o mesmo), e também a diversos aparelhos distantes de leitura e exibição de informações". O computador então deixa de ser um centro e passa a ser "um nó, um terminal, um componente da rede universal calculante", de modo que "suas funções pulverizadas infiltram cada elemento do tecnocosmos". Com efeito, "no limite, há apenas um único computador, mas é impossível traçar seus limites, definir seu contorno", ao passo que seu "centro está em toda parte e a circunferência em lugar algum", isto é, trata-se de "um computador hipertextual, disperso, vivo, fervilhante, inacabado: o ciberespaço em si” (LÉVY, 2018, p. 45).

A globalização, de acordo com Han (2019a, p. 79), "não significa simplesmente que o ali está conectado com o aqui"; ela cria - vale dizer, por intermédio do ciberespaço - "um aqui global na medida em que des-localiza e dis-tancia o ali". Ademais, de acordo com De Masi (2000, p. 142-146), a globalização envolve ao mesmo tempo um processo de [1] "achatamento da diversidade" e de [2] proliferação de "subjetividade e diferenciação". No que se refere à primeira dimensão do processo, é preciso levar em consideração variados aspectos. Assinala-se que: [1] "das pelo menos 20 mil línguas que existiam no início desse processo, atualmente parece que sobrevivem apenas sete mil, e, além disso, entre estas criou-se uma nova hierarquia"; [2] ainda que, na época do Império Romano, houvesse ocorrido algo similar em relação ao latim, tal língua era falada mormente pelas elites, ao passo que, na globalização atual, a língua inglesa (não se deixando de lado o crescimento mais recente do mandarim) passa a ser condição de navegação plena na internet destinada às massas; [3] em um plano musical, "hoje, em qualquer parte do mundo onde se tome um táxi, escuta-se no rádio um rock americano"; [4] na Amazônia, encontra-se "a mesma Coca-Cola, os mesmos guias turísticos, os mesmos telejornais de todo o resto do mundo"; [5] no âmbito da produção de bens sob o domínio de multinacionais, "vamos ao trabalho com um carro cujo design foi feito na Itália, mas cujas peças provêm de várias países, como o Japão e Coréia" (DE MASI, 2000, p. 142-146).

Quanto à dimensão da diferenciação presente na globalização, De Masi (2000, p. 116) afirma que a subjetividade adquire um certo valor. Entendida enquanto posse de "autonomia de julgamento", a subjetividade permite "uma escolha baseada em minhas necessidades e recursos, e não no fato de pertencer a algum grupo" (DE MASI, 2000, p. 116). Nesse sentido, conforme indica Han (2019a, p. 3436), a globalização "não significa racionalização", como pode parecer, assim como a cultura não segue "o logos", pois há nela algo de "incomputável" e alógico. Portanto, a nova cultura que se configura no seio do processo de globalização não tende tão-somente à homogeneização, visto que opera também se diversificando. Quanto à própria globalização, sinaliza o filósofo sul-coreano, ela será movida também por forças motrizes outras, distintas em essência de processos coercitivos de monotonia ou uniformização. Nesse sentido, "chavões como 'cultura McDonald's' ou 'cultura coca-cola' não espelham mais de modo correto a efetiva dinâmica da cultura", uma vez que, tomando a Ásia como exemplo, "McDonald's representa [...] no máximo uma pequena variedade de cozinhas locais" e "mesmo suas ofertas devem se adequar ao costume gastronômico cultural de cada um dos países". Por outro lado, não se põe em dúvida que "ofertas de racionalização como eficiência, computabilidade ou previsibilidade dominem mundialmente muitos campos da vida", mas essas tendências "não poderão pôr de lado a racionalidade da diversidade de gostos, a diversidade de condimentos e aromas" (HAN, 2019a, p. 34-36).

A partir das considerações anteriores, compreende-se por hipercultura a referida nova forma de configuração cultural engendrada no bojo do ciberespaço e da globalização virtualizada. De acordo com Han (2019a, p. 33-34), a hipercultura "não é uma monocultura superdimensional", uma vez que disponibiliza, por meio de uma rede global, "um fundo de formas e práticas de vida diferentes que se modificam, se ampliam e se renovam, nas quais passa a ocorrer também formas de vida de tempos passados" em certas condições inéditas. Han (2019a, p. 9) cogita a hipótese segundo a qual, no âmbito do mundo digital e da globalização, viveríamos em uma nova cultura, "que nos dá a liberdade de nos lançarmos como enxame na vastidão do mundo na condição de alegres turistas". Essa felicidade, assinala Han (2019a, p. 17), seria fundamentalmente distinta da "'grande felicidade nacional' cantada nos 'cantos' felizes da 'alma", pois, ao contrário desta, aquela surgiria justamente "da superação da formação em aqui, em lugar", de modo que o estrangeiro não seria visto como "doença", mas sim como "o novo que valeria

\footnotetext{
${ }^{4}$ Tal alegria aludida, porém, parece contrastar com a função constituinte da paixão na história da cultura ocidental, conforme se pode notar no desenvolvimento da obra O bom entretenimento, também de autoria de Byung-Chul Han (2019b).
} 
se apropriar" . Em outra obra, porém, Han (2018) reavalia essa situação e assinala que a liberdade dos enxames digitais se transforma em inferno à medida que engendra uma cegueira e uma estupidez embotadoras do intelecto e da sensibilidade, operando paradoxalmente novas coações, tais como a autoexploração, a autoexposição e a auto-otimização aceleradas e destituídas de sentido.

Não obstante isso, a particularidade dessa cultura global requer uma abordagem que problematize a própria noção antropológica tradicional de cultura, a qual, em contexto de análise da globalização e de encontros/choques entre povos, tende a dispor uma anteposição dos prefixos multi, inter ou trans à palavra para descrever esses processos. A esse respeito, Han (2019a, p. 97) assinala que "tanto a interculturalidade como também a multiculturalidade são em diversos sentidos um fenômeno ocidental", os quais, por um lado, do ponto de vista histórico, "estão no contexto do nacionalismo e do colonialismo"; por outro lado, do ponto de vista filosófico, "pressupõem uma essencialização da cultura". Acrescenta-se que "a nacionalização ou etnização da cultura também inspira nela uma 'alma”", de modo que "um inter deve, então, trazer as culturas essencializadas em uma relação 'dialógica" e a troca cultural "não é um processo pelo qual a cultura se deixa ser o que ela é, mas um ato especial, "digno de exploração"' (HAN, 2019a, p. 97). Buscando descrever os traços marcantes da nova cultura no início do século XXI, o filósofo sul-coreano desdobra o conceito de hipercultura nos seguintes termos:

A cultura perde cada vez mais a estrutura que se parece com a de um texto ou livro convencional.
Ela não deixa aparecer nenhuma história, teologia, teleologia como uma unidade homogênea e
significativa. Desfazem-se os limites ou as vedações nos quais a aparência de uma autenticidade
cultural ou originalidade são acentuadas. A cultura arrebenta, por assim dizer, em todas as
costuras, em todos os limites ou fendas. Fica des-limitada, sem-fronteira, des-costurada em uma
hipercultura. Não são os limites, mas os links e as conexões que organizam o hiperespaço da
cultura. [...] O processo de globalização acelera com as novas tecnologias, dis-tanciando o espaço
cultural. A proximidade que surge nesse processo produz uma plenitude, um fundo de práticas
de vida e formas de se expressar culturais. O processo de globalização atua de modo acumulativo
e condensador. Conteúdos culturais heterogêneos apinham-se em uma justaposição. Espaços
culturais se sobrepõem e se atravessam. A deslimitação é válida também para o tempo. Na
justaposição do diferente, não apenas diferentes lugares, mas também espaços de tempo
diversos ficam dis-tanciados. Não é a sensação do trans, inter ou multi, mas do hiper que
reproduz de maneira mais exata a espacialidade da cultura atual. As culturas estão se implodindo,
ou seja, estão se dis-tanciando em hipercultura (HAN, 2019a, p. 22-24).

O universo hipercultural favorecido pelo ciberespaço certamente não é isento de interesses econômicos e de relações de poder. Porém, de acordo com Han (2019a, p. 50), o desenvolvimento do mundo hipercultural é marcado também pelo "crescimento de espaços que não seriam acessíveis pelo modo do poder econômico, mas pelo estético” (HAN, 2019a, p. 49-50). A formação da identidade, nesse contexto, encontra condições inéditas de desenvolvimento.

O ciberespaço, enquanto suporte fundamental da hipercultura e fator acelerador da globalização, como qualquer outro engenho técnico, em si mesmo, não é bom nem mau. A sua potencialidade, todavia, propicia uma amplíssima variedade de usos que, por sua vez, podem receber tais qualificativos. Conforme aponta Lévy (2018, p. 25), a técnica não determina a cultura, embora a condicione, de modo que uma abordagem filosófica intransigentemente mecanicista não auxilia a compreensão de fenômenos socioculturais em seus aspectos irredutíveis a esquematismos deterministas. A esse respeito, assinala-se que "não há uma 'causa' identificável para um estado de fato social ou cultural, mas sim um conjunto infinitamente complexo e parcialmente indeterminado de processos em interação que se autossustentam ou se inibem" (LÉVY, 2018, p. 25). Por essa razão, embora seja desejável que no ciberespaço fosse cultivada a "inteligência coletiva", uma vez que tem potencial propício para isso, Lévy (2018, p. 29-30) vê "surgir na órbita das redes digitais interativas diversos tipos de formas novas...", tais como, por exemplo: [1] "de isolamento e de sobrecarga cognitiva (estresse pela comunicação e pelo trabalho diante da tela)"; [2] "de dependência (vício na navegação ou em jogos em mundos virtuais)"; [3] "de dominação (reforço dos centros de decisão e de controle, domínio quase monopolista de algumas potências econômicas sobre funções importantes da rede etc.)"; [4] "de exploração (em alguns casos de teletrabalho vigiado ou de deslocalização de atividades no terceiro mundo)"; [5] "e mesmo de bobagem coletiva (rumores, conformismo em rede ou em comunidades virtuais, acúmulo de dados sem qualquer informação, 'televisão interativa')". Por outro lado, quanto mais, no ciberespaço, fossem aprimoradas as 
formas de inteligência coletiva, melhor seria "a apropriação, por indivíduos e por grupos, das alterações técnicas, e menores são os efeitos de exclusão ou de destruição humana resultantes da aceleração do movimento tecnossocial" (LÉVY, 2018, p. 29-30).

Ademais, para além de ou em articulação com o potencial de cultivo da inteligência coletiva no âmbito do ciberespaço, o mundo desenvolvido hiperculturalmente viabiliza outra possibilidade a ser destacada. De acordo com Han (2019a, p. 48-50), o novo universo cultural favorece determinadas formas de experimentar a ludicidade, formas essas que não precisam necessariamente se traduzir em hedonismo, consumismo, narcisismo ou sociocentrismo ${ }^{5}$. Enquanto elemento de um modelo filosófico de compreensão de parte significativa do mundo atual, o conceito de hiperculturalidade distingue-se do conceito de hibridismo cultural, cuja "história conceitual, excessivamente acoplada ao complexo racista e colonialista do poder, da dominação, da opressão e da resistência, à geometria do centro e margens e de cima e baixo", deixa de considerar justamente essa ludicidade potencial da cultura que se poderia desenvolver em sintonia com campos do ciberespaço e da globalização. Essa possibilidade, a qual aponta para certa concretização do "reino do jogo e do brilho", tende a superar, por conseguinte, o "reino do poder", prometendo "mais liberdade". Parafraseando Schiller, conclui-se que a lei fundante e inviolável de tal império é "libertar pela liberdade" (HAN, 2019a, p. 48-50). Contudo, assim como o universo do trabalho tem sido transformado no sentido da geração de novas coações com base em determinadas orientações de uso do ciberespaço, também o universo da ludicidade, no âmbito hipercultural, vem sendo impactado por investidas relacionadas a interesses que, em essência, nada possuem em comum com o referido ideal schilleriano de jogo.

\section{IDENTIDADE, CORPOREIDADE E HIPERCULTURA}

As práticas socioculturais desenvolvidas no continente americano, devido ao próprio caráter da colonização que aqui se desenvolveu, propiciaram o desenvolvimento de uma globalização estreitamente vinculada com o multiculturalismo. Quando se estuda o processo de desenvolvimento de nações do Extremo Oriente, porém, patenteia-se algo distinto. Conforme assinala Han (2019a, p. 100101), "o colonialismo e a imigração, constitutivos para a multiculturalidade do Ocidente, não caracterizam o Extremo Oriente". Além disso, diferentemente de parte significativa do pensamento ocidental, "o pensamento do Extremo Oriente não se orienta pela substância, mas pela relação", de modo que, de um ponto de vista metafísico, o mundo é compreendido mais propriamente como uma "rede" e não como um "ser". Devido ao fato de tal concepção de mundo e autocompreensão asiáticas possuírem um caráter reticulado, a conectividade acelera-se "ali de modo mais intensivo do que no Ocidente". E é por essa razão que, "apesar da falta de multiculturalidade, o Extremo Oriente se manifesta cada vez mais hiperculturalmente" (HAN, 2019a, p. 100-101). Conquanto multiculturalismo e "hiperculturalismo" não se excluam - pois a hipercultura também se desenvolve a passos largos no Ocidente -, os processos de formação da identidade têm ocorrido de modos relativamente distintos nos chamados Ocidente e no Extremo Oriente.

No prelúdio deste artigo, já havíamos feito notar que a corporeidade é uma área do conhecimento e um campo da experiência estreitamente relacionado com a condição existencial humana. Podemos agora avançar e estabelecer, juntamente a Deepak Chopra (2012, p. 12-14), uma renovação da concepção tradicional de corpo. Essa renovação, alicerçada em uma filosofia que elabora suposições ancoradas em avanços da física moderna, contribui com os estudos da corporeidade à medida que fomenta um escape de uma "hipnose do condicionamento social" sistemática e coletivamente assentida. Pois bem, para realizá-lo, torna-se importante desfazermo-nos de dez ideias tradicionais vinculadas à formação da identidade. São elas: [1] "há um mundo objetivo independente do observador, e nossos corpos são um aspecto deste mundo"; [2] "o corpo é composto de conjuntos de matéria separados um do outro no tempo e no espaço"; [3] "corpo e mente são separados e independentes um do outro"; [4] "o materialismo é primário, a consciência, secundária. Em outras palavras, somos máquinas físicas que aprenderam a pensar"; [5] "a consciência humana pode ser completamente explicada como um produto da bioquímica"; [6] "como indivíduos, somos entidades desconectadas e autossuficientes"; [7] "nossa

\footnotetext{
${ }^{5}$ Chateau (1987) assinala que a educação fundada exclusivamente em práticas lúdicas "não pode triunfar sobre o egocentrismo; quando muito, pode substituir o egocentrismo individual pelo grupal, pelo sociocentrismo".
} 
percepção do mundo é automática e nos dá um quadro preciso de como as coisas realmente são"; [8] "nossa verdadeira natureza é totalmente definida pelo corpo, ego e personalidade. Somos fios de lembranças e desejos envoltos em pacotes de carne e ossos"; [9] "o tempo existe como um valor absoluto, e nós somos cativos desse absoluto. Ninguém escapa à devastação causada pelo tempo"; [10] "o sofrimento é necessário - é parte da realidade. Somos vítimas inevitáveis da doença, do envelhecimento e da morte" (CHOPRA, 2012. P. 12-14).

Chopra (2012, p. 14) sugere uma substituição desse paradigma "por uma versão mais completa e expandida da verdade". De acordo com Fritjov Capra (2019), da passagem do século XIX às primeiras décadas do século XX, a ciência física experimentou uma transformação profunda, a qual se plamou em trabalhos de pensadores tais como Einstein, Heisenberg, Bohr, entre outros. Tal transformação implicou alterações nos conceitos de "espaço, tempo, matéria, objeto, causa, efeito, etc.", isto é, em conceitos "tão básicos para o nosso modo de vivenciar o mundo". Essas alterações baseadas nas novas descobertas, por sua vez, sacudiram a "visão de mundo clássica e mecanicista" de inspiração cartesiano-newtoniana, a qual por fim teve de ser abandonada já no início do século XX pelas teorias da relatividade e quântica e que foi substituída por uma visão da natureza mais "sutil", "holística" e "orgânica". Com base em tais mudanças, Chopra (2012) faz a sugestão pela aderência a um novo paradigma, baseado nos seguintes entendimentos: [1] "O mundo físico, inclusive nossos corpos, é uma resposta do observador. Criamos os nossos corpos assim como criamos a experiência do nosso mundo"; [2] "em essência, nossos corpos são compostos de energia e informação, não de matéria sólida. Esta energia e informação são manifestações dos infinitos campos de energia e informação que alcançam todo o universo"; [3] "corpo e mente são inseparáveis. A unidade que sou 'eu' separa-se em dois cursos de experiência. Experencio o curso subjetivo como pensamentos, sentimentos e desejos. Experencio o curso objetivo como meu corpo. Em um nível mais profundo, contudo, os dois cursos se encontram em uma única fonte criativa. É a partir desta fonte que somos destinados à vida"; [4] "a bioquímica do corpo é um produto da consciência. Crenças, pensamentos e emoções criam as reações químicas que sustentam a vida de cada célula. Uma célula que envelhece é o produto final da consciência que se esqueceu de como permanecer jovem"; [5] "a percepção parece ser automática, mas na verdade é um fenômeno aprendido. O mundo onde você vive, inclusive a experiência do seu próprio corpo, é completamente ditado pelo modo como você aprendeu a percebê-lo. Se mudar a sua percepção, você mudará a experiência do seu corpo e do seu mundo"; [6] "impulsos de inteligência criam o seu corpo em novas formas a cada segundo. Você se constitui na soma total desses impulsos, e, ao mudar seus padrões, você também mudará"; [7] "embora cada pessoa pareça ser separada e independente, todos nós estamos ligados a padrões de inteligência que governam todo o cosmos. Nossos corpos são parte de um corpo universal, nossas mentes são um aspecto de uma mente universal"; [8] "o tempo não existe enquanto valor absoluto, apenas a eternidade. O que chamamos de tempo linear é um reflexo de como percebemos as mudanças. Se pudéssemos perceber o imutável, o tempo conforme o conhecemos cessaria de existir. Podemos começar a aprender a metabolizar a não mudança, a eternidade, o absoluto. Ao fazê-lo, estaremos prontos para criar a fisiologia da imortalidade"; [9] "cada um de nós habita uma realidade que jaz além de todas as mudanças. Bem no fundo, desconhecida dos cinco sentidos, existe uma essência íntima do ser, um campo de não mudança que cria a personalidade, o ego e o corpo. Este ser é a nossa essência - que somos nós de verdade"; [10] "não somos vítimas do envelhecimento, da doença e da morte. Essas coisas são parte do cenário e não daquele que vê, o qual é imune a qualquer forma de mudança. Este que vê é o espírito, a expressão do ser eterno" (CHOPRA, 2012, p. 14-16).

Após haver refletido a respeito de cada uma dessas dez novas suposições cotejando-as com aquelas do "velho paradigma", passemos a analisar como se têm desenvolvido determinados aspectos da formação da identidade em contexto hipercultural. Se, de acordo com o "novo paradigma", a unidade de nossa identidade, por um lado, separa-se em um curso de experiências subjetivas (pensamentos, sentimentos, emoções) e outro curso de experiências objetivas (corpo), e ambos os cursos, em um nível mais profundo, convergem em uma única fonte, cabe-nos indagar sobre o modo específico da experiência no hiperespaço e qual o seu impacto na formação da identidade. "O habitante do universo hipercultural", diz Han (2019a, p. 85), "seria uma espécie de essência-janela feita de windows pelas quais capta o mundo", de modo que, portanto, a identidade, nesse universo, é substancialmente distinta da concepção monadológica leibniziana. Conforme assinala Han (2019a, p. 93), "no universo leibniziano 
cada ente tem um lugar e uma identidade fixos", ao passo que, conforme vimos, no âmbito da hipercultura, "o fundo de práticas de vida e formas de se expressar" é constituído por um espaço global cujas distâncias são des-localizadas. Nesse hiperespaço, afirma Han (2019a, p. 96), "surgem estruturas e identidades ao estilo patchwork" (retalhado), quer dizer, identidades constituídas por emaranhados de componentes-windows de diversas espécies. Isso significa que, nesse universo, "nada é monadologicamente cerrado" e o "windowing", compreendido como o modo específico de experiência humana nesse hiperespaço, "toma da casa a interioridade monadológica, des-interioriza o habitante da casa em turista hipercultural" (HAN, 2019a, p. 85).

A condição existencial de "turista hipercultural", por sua vez, tem engendrado uma série de problemas de saúde, considerada em perspectiva integral. Se, como diz Han (2018), Walter Benjamin descrevia uma transformação da percepção na experiência estética do filme em termos de comparação entre a antiga contemplação e o choque provocado pela arte, este último não seria adequado para descrever mais propriamente a experiência perceptiva no mundo digital. O choque seria uma espécie de "reação imunológica", assemelhando-se à repulsa, ao passo que, hoje, à medida que as imagens que circulam na rede são investidas por uma "totalização do consumo", a experiência de windowing no hiperespaço tende à construção de formas de percepção segundo as quais "mesmo imagens repulsivas devem nos entreter", suprimindo-se assim "toda forma de contração imunológica". Ademais, acrescenta Han (2018), uma eficaz e intensa defesa imunológica sufocaria a comunicação, de modo que a promoção da cultura de aceleração da circulação de informações, propícia ao crescimento de capital, alimenta-se dessa redução da barreira imunológica. O crescimento ou fortalecimento de tal barreira tornaria a troca de informações mais lenta e reduziria o seu consumo. Não por acaso o filósofo sul-coreano indica que "não a defesa imunológica, mas sim o curtir promove a comunicação" nas redes digitais, ao passo que "a massa de informação não filtrada faz, porém, com que a percepção seja embotada". Essa situação tende a fomentar certos distúrbios psíquicos, tais como, por exemplo, a síndrome da fadiga da informação (SFI) e a depressão (HAN, 2018, p. 103-107).

Chegamos aqui à questão de facetas do sofrimento na atualidade. Ora, a décima ideia do "velho paradigma" - "o sofrimento é necessário [...] é parte da realidade", ao passo que "somos vítimas inevitáveis da doença, do envelhecimento e da morte" (CHOPRA, 2012) - exprime um beco niilista no qual se enredou parte significativa do pensamento contemporâneo. Essa concepção, de certa maneira, subjaz "práticas de vida e formas de expressar" na hipercultura. Isso se torna mais evidente à medida que se coloca em relevo o aspecto de "obscenidade" de determinadas práticas ciberculturais. Partindo da "Teoria da Obscenidade" de Sartre, Han (2017a) assinala que o corpo da sociedade, na atualidade, tem se tornado obsceno à proporção que vem sendo privado "de toda narratividade, de todo direcionamento, de todo sentido". Considerando as qualidades de excessiva quantidade e sobra da obscenidade, afirma-se ainda que um exame de tal corpo social revela determinadas "adiposidade, massificação, proliferação massiva". Além disso, "obscenas são a hiperatividade, a hiperprodução e a hipercomunicação, que se lançam velozmente para além da meta", mas também a "hiperaceleração, que não é realmente movente e tampouco nada leva adiante" (HAN, 2017a, p. 69-70). E à medida que levamos em conta a ausência de sentido de variadas "práticas de forma de vida e formas de expressar" no "mundo elaborado hiperculturalmente", não deveríamos associá-la a essa obscenidade que caracteriza a sociedade contemporânea? Certas experiências, que tendem a assumir a modalidade windowing, não seriam marcadas inconscientemente por tentativas de fugir, distrair-se, do sofrimento inevitável?

Por outro lado, se as identidades no universo hipercultural são caracterizadas por essênciasjanelas "feitas de windows pelas quais capta o mundo", deve-se considerar, porém, que a janela, diz Han (2019a), "tem duas funções": ela pode ser uma "abertura ao exterior", mas também pode ser uma proteção "do mundo". Na qualidade de tela de proteção do mundo, a janela pode contribuir com uma forma de windowing com potencial de "produzir mônadas, dessa vez mônadas com janelas cujo ser-nomundo se mostra na condição de um ser-diante-da-janela" (HAN, 2019a, p. 86). Essa particular modalidade de windowing, além de restringir consideravelmente a navegação no ciberespaço, pode contribuir, por sua vez, com a consolidação de determinados aspectos daquilo que Han (2017a) denomina "sociedade positiva". Buscando eliminar toda negatividade no sentido de se proteger do mundo por meio de algumas janelas, as identidades hiperculturais vão se formando no sentido de não se tolerar "qualquer sentimento negativo", de modo que se esquece "como se lida com o sofrimento e a 
dor" ou "como dar-lhes forma". Nesse contexto, "a sociedade positiva está em vias de reorganizar a alma de uma maneira totalmente nova", isto é, "no curso do empuxo de sua positivação, também o amor é nivelado em um arranjo de sentimentos agradáveis e de excitações complexas e sem consequências" (HAN, 2017a, p. 18-19). Contudo, a modalidade abertamente exploratória de windowing, por sua vez, é praticada por identidades em desenvolvimento que, de acordo com Han (2019a), "habitam um mundo des-mensurado em um hipermercado da cultura, em um hiperespaço de possibilidades". Nesse sentido, o filósofo sul-coreano indaga se tais turistas hiperculturais não experimentariam "mais liberdade", figurando dessa maneira uma espécie de homo liber (em contraste com o homo doloris) que começa a desfrutar de uma felicidade do porvir (Han, 2019a, p. 17-18). Caso a questão fosse respondida afirmativamente, isso se daria devido ao fato de o windowing propiciar uma "experiência particular de tempo e espaço", bem como um "modo particular de formação [Bildung] de identidade e de percepção que antes não existia” (HAN, 2019a, p. 105).

Pode-se complementar o exposto com a descrição de De Masi (2000) a respeito de uma categoria emergente de pessoas denominada "digitais". Trata-se de uma categoria sociológica que não exclui as tendências de conservação ou transformação da tradição estabelecida. Conforme indicou o sociólogo italiano, de modo similar à variedade infinita de sinfonias, que "é sempre uma resultante da combinação de apenas sete notas", também "a sociedade dá vida a sistemas sempre diversos, apesar de constituídos por sujeitos que se alimentam de sentimentos eternos como o amor, o ódio, a esperança ou o mal-estar". Não obstante essa diversidade, a globalização e a vida hipercultural haveriam condicionado certas tendências de formação da identidade dos chamados "digitais", isto é, "de um número crescente de pessoas" que passaram a adotar "um modo de viver completamente novo e diverso daquele que nos últimos séculos caracterizou a sociedade industrial". Pessoas que se enquadram nessa categoria social teriam por características uma "total intimidade com a informática e com a ubiquidade, com as conquistas da biologia e com a igual oportunidade dada a ambos os sexos", ao passo que "adoram tanto o tempo livre quanto o do trabalho, vivem a noite como vivem o dia, admiram a arte contemporânea, o design e todas as outras formas atuais de expressão artística". Eles tenderiam também ao "ecletismo, à colagem e ao patchwork". Assinala-se que ainda são denominados "digitais" não apenas "por uma identificação quase maníaca com o computador, o correio eletrônico e a Internet", mas sim porque "computador é o emblema deles, como a televisão foi o emblema da geração que se identificou com os meios de comunicação de massa, e a linha de montagem da que se identificou com a fábrica". Além disso, os "digitais" seriam sensíveis ao desenvolvimento sustentável e teriam propensão à "convivência pacífica de culturas e religiões diferentes", ao passo que não fariam "muita distinção entre os dias oficialmente úteis e os feriados oficiais". Contudo, a consolidação dos referidos traços de inovação do paradigma identitário dos "digitais" envolveria um questionamento de determinadas linhas da tradição que buscam ser conservadas por certos grupos sociais (DE MASI, 2000, p. 266-271).

Por outro lado, não deixa de haver tendências alienantes de formação identitária no universo digital. Processos de windowing, ao mesmo tempo que transformam users em turistas hiperculturais, contribuem com uma formação da identidade de modo a des-interiorizá-la. Esse processo parece implicar exatamente aquilo que Han (2017a, p. 37) assinala ser a consolidação de uma sociedade da exposição. Nesse contexto, que gera uma espécie de coação por transparência, "o valor expositivo depende sobretudo da bela aparência", desenvolvendo-se então uma "coação por beleza e por fitness". Além disso, há que se levar em conta a circulação de atuais "paradigmas" que "não transmitem qualquer valor interior, mas medidas exteriores, às quais se procura corresponder, mesmo que às vezes seja necessário lançar mão de recursos violentos" (HAN, 2017a, p. 37). O corpo, em ininterrupta adequação aos referidos paradigmas, transforma-se em mero objeto de exposição no universo hipercultural. Mas ele também passa a se tornar objeto de exploração, pois "o excesso de exposição transforma tudo em mercadoria", ao passo que "a economia capitalista submete tudo à coação expositiva, é só a encenação expositiva que gera valor, deixando de lado todo e qualquer crescimento próprio das coisas". Esse processo pode conduzir "à alienação do próprio corpo, coisificado e transformado em objeto expositivo, que deve ser otimizado" (HAN, 2017a, p. 32-33). A exposição e a exploração do corpo no hiperespaço, por sua vez, conduzem a uma situação aparentemente mais grave. Preparando o terreno para o desfecho deste artigo, analisemos a sua descrição abaixo: 
Já não é possível morar nele, sendo necessário, então, expô-lo e, assim, explorá-lo. Exposição é exploração, e seu imperativo aniquila o próprio morar. Quando o próprio mundo se transforma em espaço de exposição, já não é possível o habitar, que cede lugar à propaganda, com o objetivo de incrementar o capital da atenção do público. [...] Obscena é a hipervisibilidade, à qual falta qualquer traço de negatividade do oculto, do inacessível e do mistério. Obscenos são também os canais rasos da hipercomunicação, libertos de toda e qualquer negatividade da alteridade. Obscena é a coação de colocar tudo a mercê da comunicação ou da visibilidade. Obsceno é o pornográfico colocar corpo e alma sob foco da visão (HAN, 2017a, p. 33-34).

\section{DESFECHO}

Indagamo-nos se esse estado de coisas e se determinadas modalidades de formação da identidade em âmbito hipercultural não estão de acordo com a crença do "velho paradigma" segundo a qual "nossa verdadeira natureza é totalmente definida pelo corpo, ego e personalidade", ao passo que, nesse registro, seríamos "fios de lembranças e desejos envoltos em pacotes de carne e ossos" (CHOPRA, 2012). Perguntamo-nos também sobre até que ponto as ideias consolidadas pelo "velho paradigma" não têm contribuído com concretizações enfermiças de possibilidades do mundo hipercultural.

Todavia, ao longo do desdobramento deste artigo, fizemos notar que, do desenvolvimento do ciberespaço, emergiram possibilidades distintas, algumas delas mesmo opostas, de formação da identidade humana. Considerando a expansão da consciência e da liberdade efetuada nos termos do "novo paradigma", e com foco nas considerações segundo as quais "impulsos de inteligência criam o seu corpo em novas formas a cada segundo"; e que nós nos constituímos "na soma total desses impulsos, e, ao mudar seus padrões, você também mudará” (CHOPRA, 2012); é possível projetar e vivenciar modos mais salutares de concretizar possibilidades do hiperespaço.

Em si mesmo, o compartilhamento de parte da vida no mundo hipercultural não é necessariamente deplorável, como se poderia buscar deduzir a partir do clímax crítico explicitado ao fim do tópico anterior. Em sua avaliação, Han (2017a) parece ali indicar uma modalidade de exposição que responde a determinados imperativo, coerção e excesso, os quais não raras vezes podem ser subjetivados de modo inconsciente. Nessa linha de interpretação, não é impossível uma vivência hipercultural na qual são preservadas determinadas dimensões de sentido, privacidade e narratividade ${ }^{6}$, aqui entendidas enquanto índices de identidades harmonizadas ao "novo paradigma". Além disso, é preciso lembrar das possibilidades aludidas de experiência de uma nova ludicidade e de expansão da liberdade na hipercultura, sobretudo no que concerne à formação no âmbito da globalização, considerando-se a pluralização das diferenças identitárias, o desenvolvimento de uma consciência planetária, o fomento daquela Beleza que enfeixa a igualdade, a felicidade e a dignidade humanas...

No prelúdio deste artigo, fizemos referência a Heráclito de Éfeso, que sinalizou a dificuldade de abranger "os limites da alma, tão profundo é o seu Logos", ainda que muitos caminhos houvessem sido percorridos (frg. 45). A partir de determinadas compreensões do Logos, que, ao haverem se tornado hegemônicas, marcaram decisivamente a tradição ocidental, consolidou-se uma valorização unilateral do cálculo e da palavra no contexto de desenvolvimento da sabedoria e da ciência. Ora, consubstanciada na ideia do "velho paradigma" segundo a qual "corpo e mente são separados e independentes um do outro", tal valorização, em contrapartida, sufocou um aspecto complementar do saber, assim como fez da educação física um suposto contra-pólo de uma educação da alma. Nessa direção, enquanto os saberes da alma asfixiaram o silêncio e contribuíram com a emergência de uma "era do ruído"7 (KAGGE, 2018), os saberes do corpo tenderam a aceitar de maneira acrítica que seu objeto seria reduzido tão-somente ao movimento humano (ou à motricidade), como se o repouso fosse algo destinado exclusivamente à alma do corpo apartada. De acordo com o "novo paradigma", porém, alma e corpo são, na realidade, inseparáveis. Ao Logos, nessa perspectiva, é preciso harmonizar o silêncio, que segundo o antigo sábio

\footnotetext{
6 "Em um mundo desprovido de narrativa e de ritual, o fim só pode ser visto como uma ruptura que dói e perturba. Somente no contexto de uma narração que o fim pode ser visto como conclusão. Sem uma aparência narrativa ele sempre será uma perda e uma falta absolutas. Mas o processador não conhece narração, por isso não é capaz de conclusão” (Han, 2017a, p. 73).

7 "Levei algum tempo a aprender. Somente quando percebi que tinha uma necessidade primordial de silêncio fui capaz de partir à sua procura - e, então, soterrado sob uma cacofonia de ruídos de trânsito e pensamentos, música e máquinas, iPhones e carros limpa-neves, lá estava ele à minha espera. O silêncio” (Kagge, 2018, p. 9).
} 
egípcio Ptahotep ${ }^{8}$ (s/d, p. 62) é condição de revelação de íntimos mistérios. Ao movimento do corpo, por sua vez, torna-se importante complementar o repouso do mesmo, a fim de que sejam desenvolvidas condições de uma experiência formativa mais plena.

Se os corpos humanos não são compostos "de conjuntos de matéria separados um do outro no tempo e no espaço" (velho paradigma); e se "crenças, pensamentos e emoções criam as reações químicas que sustentam a vida de cada célula" (novo paradigma) (CHOPRA, 2012); mais do que nunca a filosofia se faz importante enquanto orientadora da boa e bela vida, ao passo que a corporeidade ganha em importância à medida que desenvolve estudos sobre os corpos concebidos como conjuntos abertos de conexões que fornecem as bases humanas de experiências da espiritualidade, da sensibilidade, do pensamento, das emoções etc. Assim sendo, o processo de alimentação deixa de ser entendido do modo restrito. Nutrimo-nos também de sensações, sentimentos, pensamentos, emoções, práticas, experiências, teorias, convivências, entendidos enquanto processos cujas energias nos atravessam por cada poro. Considerando que tudo isso inclui a nossa vida no hiperespaço, trata-se de fomentar uma educação hipercultural para a boa e bela convivência planetária, uma cultura comprometida com aspectos essenciais do novo paradigma de compreensão da formação de nossa identidade...

\section{REFERÊNCIAS}

CAPRA, F. O Tao da Física: uma análise dos paralelos entre a física moderna e o misticismo oriental.

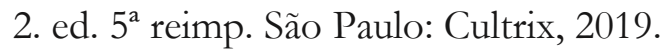

CHATEAU, J. O jogo e a criança. São Paulo: Summus, 1987.

CHOPRA, D. Corpo sem idade, mente sem fronteiras: a alternativa quântica para o envelhecimento. Rio de Janeiro: Rocco, 2012.

DE MASI, D. O ócio criativo. Rio de Janeiro: Sextante, 2000.

ESTERMANN, J. Filosofía andina: sabiduria indígena para un mundo nuevo. 2. ed. La Paz: ISEAT, 2006.

HAN, B-C. Hiperculturalidade: cultura e globalização. Petrópolis, RJ: Vozes, 2019a.

HAN, B-C. No enxame: perspectivas do digital. Petrópolis, RJ: Vozes, 2018.

HAN, B-C. O bom entretenimento: uma desconstrução da história da paixão ocidental. Petrópolis, RJ: Vozes, 2019b.

HAN, B-C. Sociedade da transparência. Petrópolis, RJ: Vozes, 2017a.

HAN, B-C. Sociedade do cansaço. $2^{a}$ ed. ampl. Petrópolis, RJ: Vozes, 2017b.

HERÁCLITO. Fragmentos. In: BORNHEIM, G. (org.). Os filósofos pré-socráticos. São Paulo: Cultrix, 1998.

KAGGE, E. Silêncio na Era do Ruído. 1ª reimp. Lisboa: Quetzal, 2018.

LÉVY, P. Cibercultura. 3ª ed. $3^{\text {a }}$ reimp. São Paulo: Editora 34, 2018.

8 "Vizir do faraó Dedkarê-Iséri, penúltimo monarca da 5ª dinastia, que teria exercido o poder nos 2.668-2.640 a.C.” (Xavier, s/d, p. 59). 
MOREIRA, W. W.; SIMÕES, R. Educação física, esporte e corporeidade: associação indispensável. In: MOREIRA, W. W.; NISTA-PICCOLO, V. (Orgs). Educação física e esporte no século XXI.

Campinas: Papirus, 2016. p. 133-152.

PTAHOTEP. Provérbios. In: XAVIER, R. (org.). Textos sagrados das pirâmides. Rio de Janeiro: Livros do Mundo Inteiro, s/d.

SCHILLER, F. A educação estética do homem: numa série de cartas. $10^{a}$ reimp. São Paulo: Iluminuras, 2017.

Submetido: $13 / 08 / 2020$

Aprovado: $26 / 10 / 2020$ 